\title{
GLICOLIPOPROTEÍNA DE LEPTOSPIRA INTERROGANS SOROGRUPO ICTEROHAEMORRHAGIAE: DISTRIBUIÇÃO EM FÍGADO E RIM DE COBAIAS EXPERIMENTALMENTE INFECTADAS
}

\author{
R.T. MACÊDO SANTOS (1), E.E. SAKATA (2), P.H. YASUDA (3), A. WAKAMATSU (1), C.T. KANAMURA (1),
} I. CANDELORI (1), C.B. PESTANA (1) \& V.A.F. ALVES (1)

\begin{abstract}
RESUMO
Acredita-se que as lesões teciduais na leptospirose possam decorrer da ação direta das leptospiras, de toxinas sintetizadas ou liberadas durante sua lise. O presente estudo visou a extração química da glicolipoproteína (GLP) da leptospira, a produçào de anti-soro anti-GLP e a avaliação de sua distribuição em cortes de fígado e rim de cobaias inoculadas e sacrificadas em estudo sequencial diário até o $6^{\circ}$ dia de infeção, correspondente ao pico da doença. Procurou-se também correlacionar a expressão tecidual da GLP com o grau de lesões locais, em busca de novos subsídios para a compreensão da patogenia da leptospirose. A GLP foi detectada em fígado e rim de 2 dentre 6 cobaias no 5!" dia e em todas as 6 no 6. dia de infecção, sob a forma de grânulos no citoplasma de macrófagos, livres no interstício ou acolados à membrana de células endoteliais e parenquimatosas, especialmente nas regiões mais lesadas. A cronolugia do aparecimento da GLP e sua distribuição sugerem tratar-se de produto de lise de leptospiras fagocitadas por macrófagos e que esta substância, conquanto nào conprovada como iniciadora das lesōes, associa-se a seu agravamento nas etapas mais avançadas da leptospirose.
\end{abstract}

I NTERMOS: Glicolipoproteina; Leptospirose; Imunohistoquímica.

\section{INTRODUÇÃO}

Estudos clínicos e anátomo-patológicos da leptospirose têm sugerido que as lesões ou as disfunções orgânicas possam ser causadas pela ação direta das leptospiras; por toxinas elaboradas por essas bactérias ou liberadas durante a sua lise $2,4,5,6,9,10,11,23,29$. Diversas tentativas de isolamento e caracterização de possíveis fatores tóxicos, foram realizadas por STALHEIM ${ }^{24}$, MILLER e cols. ${ }^{19}$, JACKSON \& ZEY ${ }^{16}$, KNIGHT e cols. ${ }^{17}$ e FAINE e cols. ${ }^{15}$. A ação citotóxica do sorotipo pomona sobre cultura de fibroblastos foi demonstrada por YAM e cols.28, sem entretanto caracterizar a natureza química responsável por essa atividade tóxica. Já, VINH e cols. ${ }^{27}$ extrairam do sorotipo copenhageńi, tanto de cepas virulentas quanto de cepas avirulentas, uma glicolipoproteína (GLP) de efeito citotóxico sobre fibroblastos de camundongos e sugeriram ser o componente lipídico dessa GLP o fator responsável por essa toxicidade.

(1) Divisâo de Patologia, lnstituto Adolto Luk. São Paulo, SP, Brasil.

(2) Seçào de Bacteriologia, Instituto Adolfo Luiz. Sào Paulo, SP, Brasil.

(3) Instituto de Ciências Bionédicas da Universidade de Sào Paulo. São Paulo, SP, Brasil.

Fndereço para correspondência: Dr. Venâncio A.F. Alves. Divisão de Patologia, Instituto Adolfo Lutz. Av. Dr. Arnaldo, 355. Caiva Posral 7027. CEP 01246 Sào Paulo, SP, Brasil. 
SANTOS, R.T.M.; SAKATA, E.E.; YASUDA, P.H.; WAKAMATSU, A.; KANAMURA, C.T .; CANDELORI, I.; PESTANA, C.B. \& ALVES, V.A.F. - Glicolipoproteina de Leptospira interrogans sorogrupo icterohaemorrhagiae: distribuiçào em fígado e rim de cobaias experimentalmente infectadas. Rev. Inst. Med. trop. S. Paulo, 31(4):235-241, 1989.

Tendo em vista novos subsídios à compreensão da patogenia da leptospirose, o presente estudo teve como objetivo a extração química da glicolipoproteína (GLP) de lepstospira, a produção de anti-soro de coelho anti-GLP e, através de técnicas imunohistoquímicas, a avaliação de sua presença em tecidos de cobaias inoculadas experimentalmente.

\section{MATERIAL E MÉTODOS}

Extração da GLP - A amostra utilizada foi a cepa 15/86 isolada de paciente internado no Hospital Emilio Ribas e tipificada como sendo do sorotipo monymusk do grupo Icterohaemorrhagiae de L. interrogans, pela técnica de absorção cruzada de aglutininas.

Segundo a técnica de VINH e cols. ${ }^{27}$, a cultura de 7 dias à $30^{\circ} \mathrm{C}$ em meio EMJH (Difco) foi centrifugada e seu sedimento ressuspenso

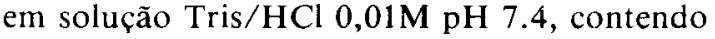
$50 \mathrm{mcg}$ de lisozima (Sigma) e incubado por 18 horas a $34^{\circ} \mathrm{C}$. As leptospiras assim tratadas foram submetidas a nova centrifugação a 20.000 $\mathrm{x} g$ por 30 minutos e seu sobrenadante foi tratado com uma mistura de $50 \mathrm{mcg} / \mathrm{ml}$ de RNAse e de DNAse (Sigma) por 3 horas a $37^{\circ} \mathrm{C}$. A seguir foi realizada diálise com solução tampão Tris $/ \mathrm{HCl} \mathrm{pH} 7.4$ por 24 horas a $4^{\circ} \mathrm{C}$ e o dialisado foi acidificado até pH 3.7 com solução de ácido acético $1 \mathrm{M}$. Formou-se então um precipitado, correspondente à glicolipoproteina (GLP), que foi centrifugado a $37.000 \times \mathrm{g}$ por 30 minutos e lavado 2 vezes com ácido acético O.1M.

Obtenção de anti-GLP em coelho $-2 \mathrm{mg}$ de GLP (peso úmido) foram ressuspensos em PBS, emulsionados $v / v$ com adjuvante incompleto de Freund e injetados intradermicamente em coelhos de $4 \mathrm{~kg}$. Após 3 semanas, procedeu-se à sangria de prova e o teor de anticorpos anti-GLP foi dosado pela reação de soroaglutinação microscópica, empregando a própria ce.pa $15 / 86$.

Reprodução experimental da leptospirose em cobaias - Foi realizado um estudo sequencial diário até o $6^{\circ}$ dia de infecção utilizando 30 cobaias recém-desmamadas, pesando de 170 a 200 gramas e inoculadas com a cepa $15 / 86$. Os grupos foram assim constituidos:

Grupo 1: 2 cobaias sacrificadas no $1^{\circ}$ dia após inoculação
Grupo 2: 2 cobaias sacrificadas no $2{ }^{\circ}$ dia após inoculação

Grupo 3: 2 cobaias sacrificadas no 3. dia após inoculação

Grupo 4: 6 cobaias sacrificadas no 4 . dia após inoculação

Grupo 5: 6 cobaias sacrificadas no 5\% dia após inoculação

Grupo 6: 6 cobaias sacrificadas no 6: dia após inoculação

Cada cobaia dos grupos teste (1 a 6) foi inoculada por via intraperitoneal com $1 \mathrm{ml}$ de cultura, de 5 a 7 dias a $28-30^{\circ} \mathrm{C}$ em meio Fletcher e com densidade aproximada de 10 a 10 leptospiras/ml. Antes de serem sacrificadas, as cobaias foram submetidas à punção intracardíaca para obtenção de retrocultura como testemunho da etiologia.

O grupo-controle (grupo O) constituido de 6 cobaias, foi inoculado com $1 \mathrm{ml}$ de meio Fletcher estéril.

Após o sacrifício, seguiu-se um exame macroscópico e a retirada de fragmentos de fígado e rim que, após fixação em solução de Bouin, desidratação em álcoois, diafanização em xilóis e inclusão em parafina, foram seccionados a 4 micrômetros para análises imunohistoquímicas.

Anti-soro - Soro total de coelho anti-GLP de leptospira, absorvido com pó de fígado e rim de cobaias normais na proporção de $0,1 \mathrm{~g} / \mathrm{ml}$ de soro diluido $1 / 2$ durante uma noite, foi centrifugado a $3.000 \mathrm{xg}$ por 15 minutos, sendo o sobrenadante utilizado como anticorpo primário na diluição $1 / 40$. Como anticorpo secundário foi empregado soro de cabra anti-IgG de coelho diluido $1 / 50$, obtido comercialmente (Diagnostic Reagents, USA). A amplificação fói feita pelo uso do complexo peroxidase anti-peroxidase (PAP) obtido em coelho (Dako, USA), diluido $1 / 2000$.

Protocolo Imunohistoquímico - Foi utilizado o método de anticorpos não-conjugados, descrito por STERNBERGER e cols. ${ }^{25}$ modificado às nossas condições laboratoriais, de acordo com ALVES e cols. ${ }^{1}$, sendo agora introduzida a pré-digestão protéica com tripsina tipo II de pâncreas de porco (Sigma, USA) , $15 \mathrm{mg} \%$ em tampão PBS 0,01M, contendo $134 \mathrm{mg} \%$ de cloreto de cálcio, ajustando-se o $\mathrm{pH}$ a 7.8 , por 15 minutos a $37^{\circ} \mathrm{C}$ e a incubação com o anticorpo primário por 24 horas a $4^{\circ} \mathrm{C}$. 
SANTOS, R.T.M.; SAKATA, E.E.; YASUDA, P.H.; WAKAMATSU, A.; KANAMURA, C.T.; CANDELORI, I.; PESTANA, C.B. \& ALVES, V.A.F. - Glicolipoproteína de Leptospira interrogans sorogrupo icterohaemorrhagiae: distribuição em figado e rim de cobaias experimentalmente infectadas. Rev. Inst. Med. trop. S. Paulo, 31(4):235-241, 1989.

\section{Controles negativos:}

1 - Casos-controle (grupo O) foram sempre submetidos às mesmas pesquisas de antígenos efetuadas nos demais grupos.

2 - Foi aplicada reação a cortes de tecido sabidamente positivos para o antígeno, mas omitindo-se a incubação com anticorpo primário.

3 - Idem, omitindo-se a incubação do anticorpo secundário.

4 - Idem, omitindo-se a incubação do complexo de amplificação.

5 - Idem, com incubação do sobrenadante resultante da absorção do anticorpo primário com excesso de GLP de leptospira.

Análise imunohistoquímica: A análise dos preparados foi efetuada por um único observador (V.A.F.A.), visando avaliar qualitativamente a distribuição da GLP nas estruturas hepáticas e renais das cobaias experimentalmente infectadas.

\section{RESULTADOS}

Nenhum dos controles negativos apresentou qualquer coloração à pesquisa imunohistoquímica, o mesmo sucedendo com as cobaias sacrificadas no $1 \stackrel{\circ}{\circ} 2^{\circ}, 3$. e $4^{\circ}$. dias.
A glicolipoproteína foi encontrada no tecido hepático e renal apenas a partir do $5^{\circ}$ dia de infecção, com padrão granuloso ou de curtos bastões.

No tecido hepático, dentre os casos do grupo 5 , apenas as cobaias 5.1 e 5.6 mostraram-se positivas, notando-se raros grânulos no citoplasma de macrófagos, livres no interstício ou acolados à miembrana de células endoteliais. Por outro lado, no 6. dia de infecção, todos os casos apresentaram número variável de grânulos no citoplasma de macrófagos (Fig. 1), livres no interstício ou acolados à membrana de células endoteliais e de hepatócitos (Fig. 2). Raros grânulos foram ainda visualizados no citoplasma destes últimos.

No tecido renal, no grupo 5 , apenas as cobaias 5.1 e 5.6 exibiram raros grânulos de glicolipoproteina no citoplasma de macrófagos, livres no interstício ou na membrana de células endoteliais. Já no $6^{\circ}$ dia, todas as cobaias apresentaram número variável de grânulos ou bastões em macrófagos (Fig. 3), livres no intersticio ou na luz dos túbulos contornados em seus diversos segmentos, sendo também vistos acolados à membrana de células endoteliais e do epitélio tubular.

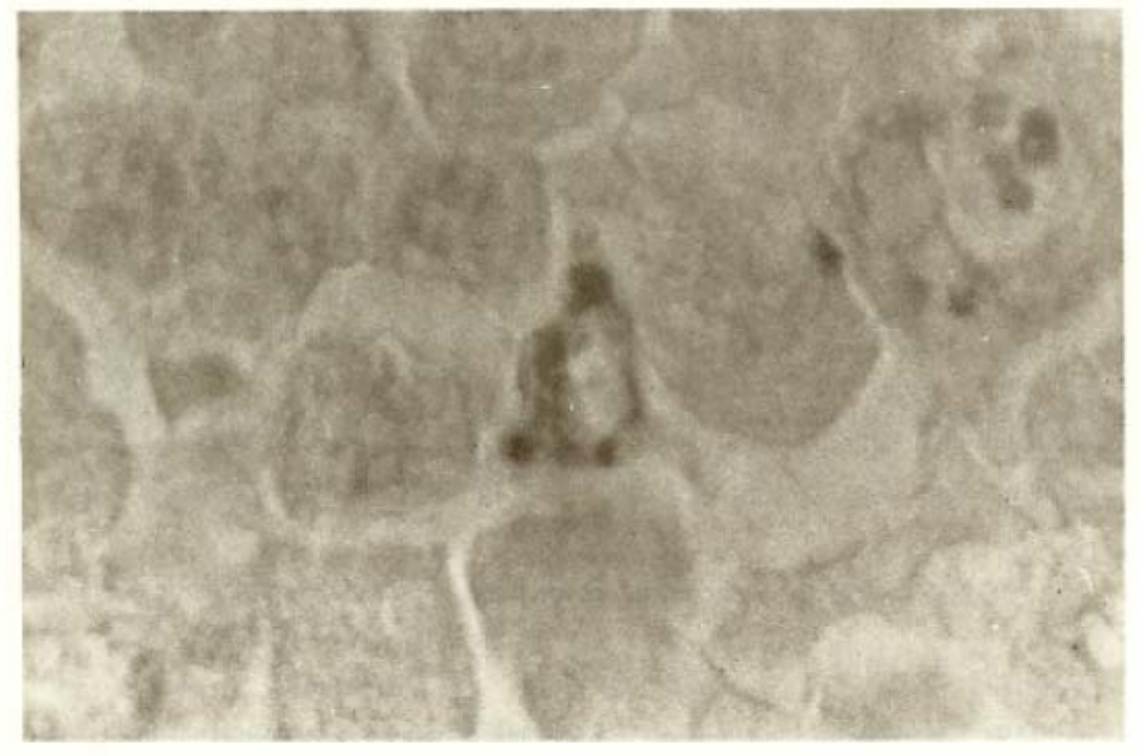

Fig. 1 - Caso 6.1 - Glicolipoproteina de leptospira, sob forma de granulos grosseiros, te encontrada predominantemente no citoplasma de células de Kupffer. (1000 x PAP). 
SANTOS, R.T.M.; SAKATA, E.E.; YASUDA, P.H.; WAKAMATSU, A.; KANAMURA, C.T.; CANDELORI, I.; PES-

TANA, C.B. \& ALVES, V.A.F. - Glicolipoproteína de Leptospira interrogans sorogrupo icterohaemorrhagiae: distribuição em fígado e rim de cobaias experimentalmente infectadas. Rev. Inst. Med. trop. S. Paulo, 31(4):235-241, 1989.

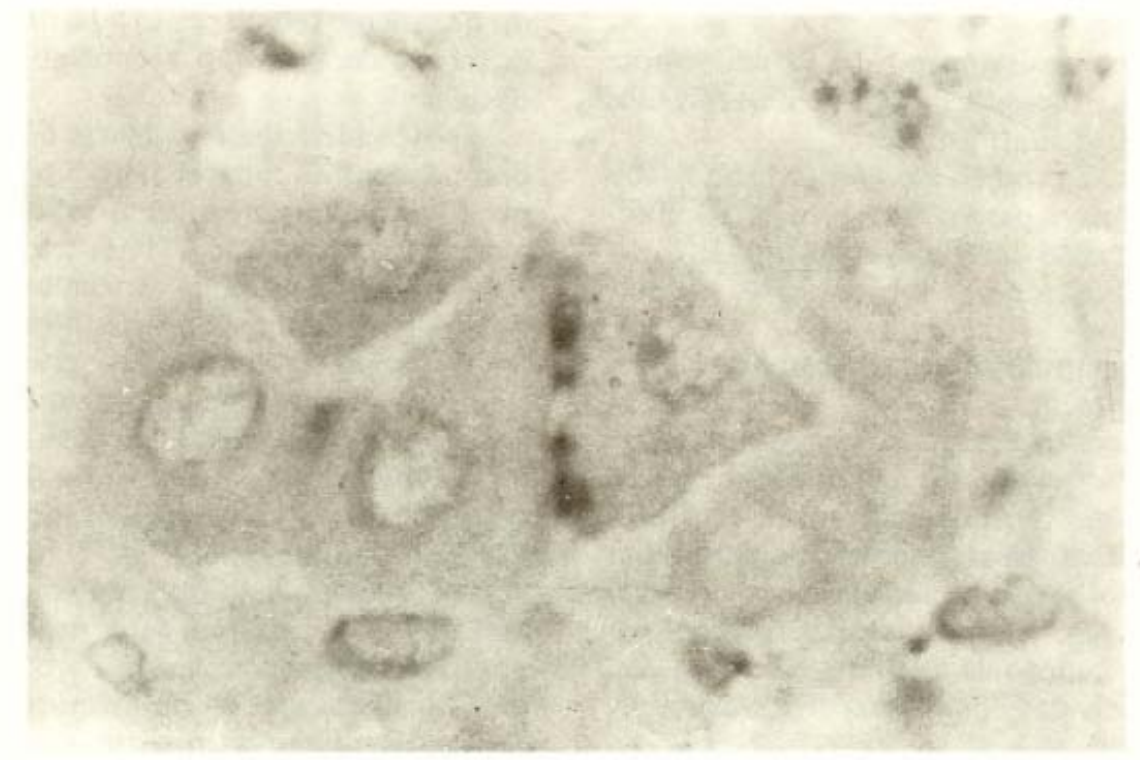

Fig. 2 - Caso 6.3 - Glicolipoproteina de leptospira aderida à membrana de hepatócitos em destrabeculaçấo. (1000 x PAP).

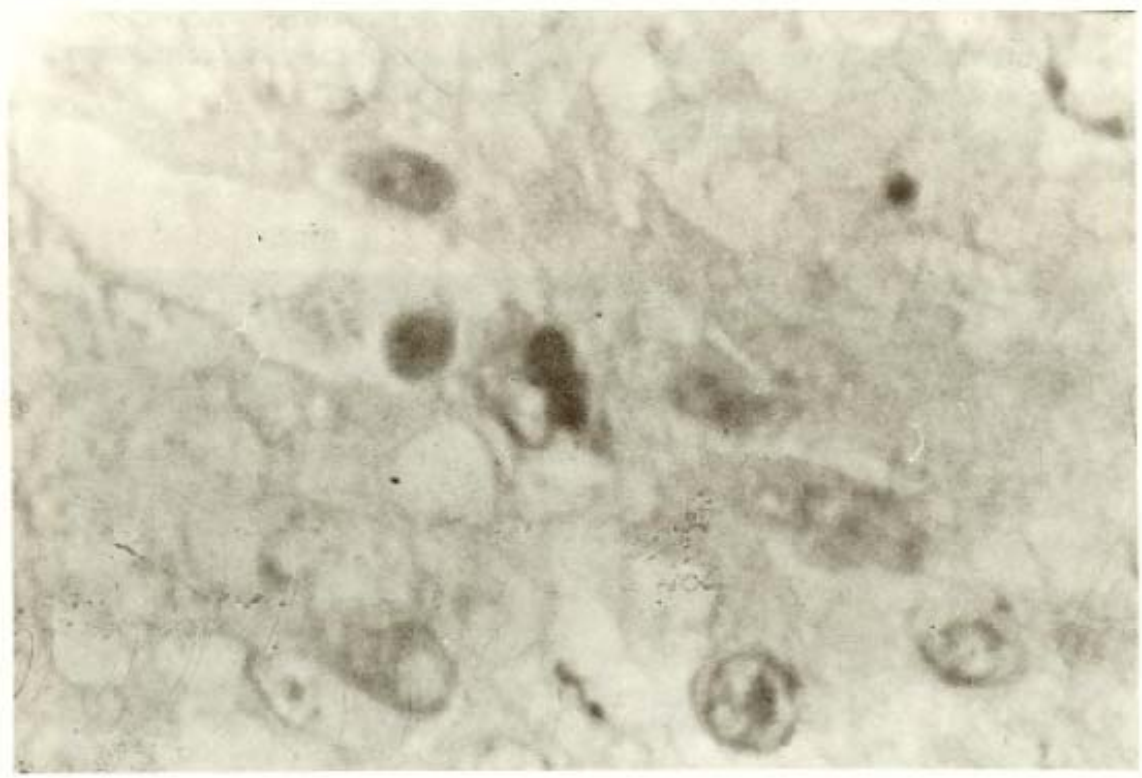

Fig. 3 - Caso 6.1 - Grânulos de glicolipoproteina de leptospira fagocitados por macrófagos no interstício renal (1000 $\mathrm{x}$ PAP).

\section{DISCUSS̃̃O}

Para o estudo das lesões máximas da leptospirose icterohemorrágica, selecionamos dentre as coleções de cultura de $\mathbf{L}$. interrogans so- rogrupo Icterohaemorrhagiae do Instituto Adolfo Lutz e Instituto de Ciências Biomédicas da Universidade de São Paulo, uma cepa $(15 / 86)$ isolada de paciente internado no Hospital Emilio Ribas com quadro clínico exuberan- 
SANTOS, R.T.M.; SAKATA, E.E.; YASUDA, P.H.; WAKAMATSU, A.; KANAMURA, C.T.; CANDELORI, I.; PESTANA, C.B. \& ALVES, V.A.F. - Glicolipoproteina de Leptospira interrogans sorogrupo icterohaemorrhagiae: distribuição em figado e rim de cobaias experimentalmente infectadas. Rev. Inst. Med. trop. S. Paulo, 31(4):235-241, 1989.

te, incluindo icterícia, insuficiência renal aguda e diátese hemorrágica. A absorção cruzada de aglutininas, foi confirmada sua classificação no sorogrupo Icterohaemorrhagiae, sendo identificado como sorotipo monymusk.

Este estudo, com sacrifício sequencial diário de animais do $1^{\circ}$ ao $6^{\circ}$ dia de infecção, demonstrou-se suficiente para análise de todo o espectro da doença já que, no último dia do experimento três das cobaias evoluiram para morte espontânea, encontrando-se outras duas em fase agônica quando do sacrifício.

A detecção de antígenos específicos das leptospiras mediante imunohistoquímica enzimática, foi publicada por ELLIS e cols. (1983) ${ }^{14}$ que exploraram a expressão de antígenos em tecido de rim de porcos com objetivos de diagnóstico veterinário. Esses autores valorizaram apenas as estruturas antigênicas com formato de leptospiras íntegras e mostraram a alta sensibilidade e especificidade do método quando comparado com o diagnóstico obtido por cultura de leptospiras. No primeiro estudo referindo deteç̧ão imunohistoquímica enzimática de antígeno de leptospira em rim de cobaia! empregamos o complexo peroxidase anti-peroxidase. A seguir, constatamos a presença de antígeno de leptospira em tecidos humanos hepáticos e renais, comprovando a utilidade do método para diagnóstico em autópsias ${ }^{2}$. Foi também esta a metodologia que usamos em recente estudo de lesões vasculares e cardíacas na leptospirose ${ }^{12}$.

Estas experiências prévias levaram-nos a escolher o complexo peroxidase anti-peroxidase para a amplificação das reações com antígenos de leptospira.

Os anticorpos usados foram preparados a partir da própria cepa $15 / 86$, empregada na inoculação de cobaias. Ressalte-se que, no presente estudo, o antígeno utilizado na produção de anti-soro consistiu apenas da glicolipoproteina GLP, extraida desta leptospira. Para obtenção de maior contraste foram efetuadas algumas modificaçoes no método que descrevemos originalmente', sendo agora introduzida a prédigestão proteica com tripsina e a incubação com o anticorpo primário por 24 horas.

A imunohistoquímica enzimática com emprego de peroxidase tem dentre suas principais caracteristicas favoráveis a aplicabilidade a tecidos fixados e incluidos rotineiramente, desde que os antígenos não sejam totalmente destruidos por estes procedimentos, a manutenção da coloraçào por tempo indefínido e a possibilida- de de análise à microscopia óptica convencional $13,18,21,22,26$.

A amplificação pelo complexo peroxidase anti-peroxidase (PAP)2s, acarreta grande sensibilidade devido à formação de imunecomplexos mais volumosos, à estrutura cíclica do complexo PAP, que the confere grande estabilidade, $\mathrm{e}$ à ausência de ligaçōes covalentes entre a enzima e os anticorpos envolvidos, não diminuindo a afinidade imunológica dos mesmos $7,8,20$.

Conquanto a maioria dos estudiosos atribua a formação das lesões teciduais na leptospirose a efeito tóxico ligado às leptospiras, restam importantes questões sobre a participação direta do microorganismo através de sua movimentação ativa, como propuseram SITPRIJA e cols. ${ }^{23}$, bem como a de seus componentes. Estes poderiam incluir produtos de síntese bacteriana ou corresponder a substâncias liberadas durante sua lise ${ }^{2,29}$. Recentemente, VINH e cols.27 extraíram uma glicolipoproteína a partir de cultura de $\mathbf{L}$. interrogans sorotipo copenhageni e demonstraram sua toxicidade direta em fibroblastos de camundongos.

A glicolipoproteína extraida da leptospira, segundo método de VINH e col.27, foi pela primeira vez detectada em tecido hepático e renal no presente trabalho, mostrando-se em pequena quantidade em apenas 2 casos no $5^{\circ}$. dia e em abundância no $6^{\circ}$ dia de infecção. Sua localização no fígado deu-se no citoplasma de células de Kupffer, nas membranas de células endoteliais e de hepatócitos. No rim, foram evidenciadas no citoplasma de macrófagos, livres no interstício e no epitélio ou luz tubular.

Em estudo recente ${ }^{3}$, observamos que neste modelo experimental, as lesões hepáticas e renais iniciam-se no $4{ }^{\circ}$ dia, crescendo até um pico no $6^{\circ}$ dia de infecção, quando as cobaias sucumbem espontaneamente ou encontram-se em fase agônica.

A cronologia do aparecimento da GLP nos tecidos, bem como sua distribuição, sugerem que esta substância seja um dos produtos de lise das leptospiras quando fagocitadas pelos macrófagos.

Esta GLP, que foi recentemente extraida e demonstrada como citotóxica ${ }^{27}$, neste estudo esteve presente nos últimos dois dias de infecção exatamente nos locais de alterações máximas. Tal achado sugere que esta substância, conquanto não comprovada como iniciadora da lesão nesta infecção de cobaias, possa se as- 
SANTOS, R.T.M.; SAKATA, E.E.; YASUDA, P.H.; WAKAMATSU, A.; KANAMURA, C.T,; CANDELORI, I.; PESTANA, C.B. \& ALVES, V.A.F. - Glicolipoproteina de Leptospira interrogans sorogrupo icterohacmorrhagiae: disiribuição en fígado e rim de cobaias experimentalmente infectadas. Rev. Inst. Med. trop. S. Paulo, 31(4):235-241, 1989.

sociar a seu intenso agravamento na fase final da doença.

\section{SUMMARY}

\section{Glycolipoprotein from Leptospira interrogans serogroup icterohaemorrhagiae: immunohistochemical expression in liver and kidney of experimentally infected guinea-pigs.}

Tissue damage in leptospirosis has been ascribed to direct effect of the microorganisms and/or their virulence, including products synthetised by leptospires or rele?sed during their lysis. This study aimed at chemical extraction of the glycolipoprotein (GLP) from virulent leptospires, production of a rabbit anti-GLP and analysis of its distribution in liver and kidney of inoculated guinea-pigs, sacrificed sequentially from the $1^{\text {st }}$ to $6^{\text {th }}$ day of infection, covering the whole, spectrum of acite leptospirosis. The comparison of GLP expression to local injuries aimed at new pathogenetic data. GLP was detected in liver and kidney in 2 out of 6 guinea-pigs on the $5^{\text {th }}$ day and in all 6 animais on the $6^{\text {th }}$ day of infection. Granular forms were seen in the cytoplasm of macrophages, free in interstitium or adhered to endothelial and parenchimal cell membranes, especially in the most damaged sites. These findings lead us to the hypothesis of GLP as a toxic factor resulting from leptospiral lysis by macrophages. Although it was not proved as a promoter of initial lesions, it seems to be related to the enhancement of tissue damage late in the course of the disease.

\section{REFERÊNCIAS RIBLIOGRÁFICAS}

1. ALVES, V.A.F.; YASUDA, P.H.; YAMASHIRO, E.H.; SANTOS, R.T.M.; YAMAMOTO, L.U. \& DE BRITO, T. - An immunohistochemic assay to !ocalize leptospires in tissue specimens. Rev. Inst. Med. trop. S. Palilo, 28:170-1\%3, 1986.

2. ALVES, V.A.F.; VIANNA, M.R.; YASUDA, P.H. \& DE ERITO, T. - Detection of leptospiral antigen in the human liver and kidney using an immunoperoxidase staining procedure. J. Path., 151:125-131, 1987.

3. ALVES, V.A.F. - Leptospirose experimental em cobaik: contribuição de dados morfológicos e imunohistoquímicos para a compreensão de sua patogenia. São
Paulo, 1988. (Tese de Doutoramento - Faculdade de Medicina da Universidade de São Paulo).

4. AREAN, V.M. - Studies on the pathogenesis of leptospirosis. II - A clinicopathologic evolution of hepatic and renal function in experimental leptospiral infections. Lab. Invest., 11:273-288, 1962.

5. ARRIAGA, A.J.D.; ROCHA, A.S.; YASUDA, P. \& DE BRITO, T. - Morpho-functional patterns of kidney injury in the experimental leptospirosis of the guinea-pig (L. icterohaemorrhagiae). J. Path., 138: 145-161, 1982,

6. AUSTONI, M. \& CORA, D. - The pathogenesis of kidney damage in human leptospirosis. Trop. geogr. Med., 13:20-26, 1961.

7. BELLON, B.; SAPIN, C. \& DRUET, P. - Comparaison de la sensibilité des techniques d'immunofluorescence et d'immunoperoxidase in methodes directe et indirecte. Ann. Immunol. (Paris), 126c:15-22, 1975.

8. BURNS, J.; HAMBRIDGE, M. \& TAYLOR, C.R. Intracellular immunoglobulins: a comparative study on three standard tissue processing methods using horseradish peroxidase and fluorochrome conjugates. J. clin. Path., 27:548-557, 1974.

9. DE BRITO, T. - Lesðes renais e hepáticas na leptospirose experimental do cobaio. Ribeiråo Preto, 1965. (Tese de Livre Docência - Faculdade de Medicina de Ribeirão Preto).

10. DE BRITO, T.; PENNA, D.; SANTOS, H.; FREY MULLER, E.; ALMEIDA, S.S.; GALVÃO, P.A.A. \& PEREIRA, V. - Electron microscopy of human leptospirosis (kidney tiopsies). Amer. J. Med., 14:397$403,1965$.

11. DE BRITO, T.; PENNA, D.O.; PEREIRA, V.G. \& HOSHINO, S. - Kidney biopsies in human leptospirosis: a biochemical and electron microscopy study. Virchows Arch. Path. Anat. 343:124-135, 1967.

12. DE BRITO, T.; MORAIS, C.F.; YASUDA, P.H.; LANCELLOTI, C.P.; SHIMIZU, S.H.; YAM iSHIRO, E. \& ALVES, V.A.F. - Cardiovascular involvement in human and experimental leptospirosis: Pathologic fingings and immunohistochemical detection of leptospiral antigen. Ann. trop. Med. Parasit., 81:207. $214,1987$.

13. DE LELLIS, R.A.; STERNBERGER, L.A.; MANN, R.B.; BANKS, P.M. \& NAKANE, P.K. - Immunoperoxidase techniques in diagnosis pathology. Amer. J. clin. Path., 71:483-488, 1979.

14. ELLIS, T.M.; ROBERTSON, G.M.; HUSTAS, L. \& KIRBY, M. - Detection of leptospires in tissue using an immunoperoxidase staining procedure. Aust. vet. J., 60:364-367, 1983.

15. FAINE, S.; ADLER, B. \& PALIT, A. -- Chemical and serological properties of a serotype-specific polysaccharide antigen in Leptospira. Aust. J. exp. Biol. med. Sci., 52:311-319, 1974 .

16. JACKSON, S.W. \& ZEY, P.N. Ultrastructure of lipopolysaccharide isolated from Treponema pallidum. J. Bact., 114:838-844, 1973.

17. KNIGHT, L.L.; MILLER, N.G. \& WHITE, R.J. Cytotoxic factor in the blood and plasma of animals during leptospirosis. Infect. Immun., 8:401-405, 1973.

18. MESA-TEJADA, R.; PASCAL, R.R. \& FENOGLIO, C.M. - Immunoperoxidase: a sensitive immunohistochemical technique as a "special stain" in the diagnostic pathology laboratory. Hum. Path., 8:313-320, 1987. 
SANTOS, R.T.M.; SAKATA, E.E.; YASUDA, P.H.; WAKAMATSU, A.; KANAMURA, C.T.; CANDELORI, I.; PESTANA, C.B. \& ALVES, V.A.F. - Glicolipoproteína de Leptospira interrogans sorogrupo icterohaemorrhagiae: distribuição em fígado e rim de cobaias experimentalmente infectadas. Rev. Inst. Med. trop. S. Paulo, 31(4):235-241, 1989.

19. MILLER, N.G.; FOREHLING, R.C.\& WHITE, R.S. - Activity of leptospires and their products on $L$ cells monolayer. Amer. J. vet. Res., 31:371-377, 1970.

20. MORIARTY, G.C.; MORIARTY, C.M. \& STERNBERGER, L.A. - Ultrastructural immunocytochemistry by unlabelled antibodies and the PAP complex. A technique more sensitive than radioimmunoassay. J. Histochem. Cytochem., 21:825-833, 1973.

21. NAKANE, P.K. \& PIERCE, G.B. - Enzyme-labelled antibodies preparation and application for the localization of antigens. J. Histochem. Cytochem., 14:929938, 1966.

22. PINKUS, G.S. - Diagnostic immunocytochemistry of paraffin-embedded tissues. Hum. Path., 13:411-415, 1982.

23. SITPRIJA, V.; PIPATANAGUL, V.; MERTOWIDJOJO, K.; BOONPUCKNAVIG, V. \& BOONPUCK NAVIG, S. - Pathogenesis of renal disease in leptospirosis: Clinical and experimental studies. Kidney Int., 17:827-836, 1980.

24. STALHEIM, O.H.V. - A toxic factor in Leptospira pomona. Proc. Soc. exp. Biol. Med., 126:412-415, 1967.
25. STERNBERGER, L.A.; HARDY, P.H.; CUCULIS, J.J. \& MEYER, H.G. - The unlabelled antibodyenzyme method of immunohistochemistry. Preparation and properties of soluble antigen-antibody complex (PAP) and its use in identification of spirochetes. J. Histochem. Cytochem., 18:315-333, 1970.

26. TAYLOR, C.R. - Immunoperoxidase techniques: practical and theoretical aspects. Arch. Path. Lab. Med.. 102:113-121. 1978.

27. VINH, T.; ADLER, B. \& FAINE, S. - Glycolipoprotein cytotoxin from Leptospira interrogans serovar copenhageni. J. gen. Microbiol., 132:111-123, 1986.

28. YAM, P.A.; MILLER, N.G. \& WHITE, R.J. - A leptospiral factor producing a cytophatic effect on $\mathrm{L}$ cells. J. infect. Dis., 122:310-317, 1970.

29. YASUDA, P.H.; SHIMIZU, S.H.; YAMASHIRO, E.H. \& DE BRITO, T. - Experimental leptospirosis (L. interrogans serovar icterohaemorrhagiae) of the guinea pig: leptospiral antigen, gamma globulin and complement C3 detection in the kidney. Exp. Path., 29:35-43, 1986.

Recebido para publicação em 9/2/1989. 